\title{
Group B streptococcal colonization in mothers and infants in western China: prevalences and risk factors
}

\author{
Jichang Chen ${ }^{1 \dagger}$, Jinjian $\mathrm{Fu}^{2+}$, Wei Du, ${ }^{3,4}$, Xin $\mathrm{Liu}^{5}$, Chokechai Rongkavilit ${ }^{6}$, Xuemei Huang ${ }^{1}$, Yubi Wu',
} Yuanliu Wang ${ }^{7}$ and Eric McGrath $3,4,8^{*}$ (D)

\begin{abstract}
Background: The epidemiology of maternal and infant Group B streptococcus (GBS) colonization is poorly understood in China. The aim of this study is to explore the prevalence and risk factors associated with maternal and infant GBS colonization in Western China.

Methods: From January 2017 to June 2017, a prospective study was conducted to estimate the maternal and infant GBS colonization rate by maternal rectovaginal and infant nasopharynx, ear canal and umbilical swab culture. Patient demographics, clinical characteristics and outcomes were collected. Chi-square and logistic regression analyses were used to examine the risk factors associated with GBS colonization of mothers and infants.

Results: The GBS colonization rate in mothers and infants was 6.1 and $0.7 \%$, respectively. The vertical transmission rate was $7.6 \%$. The early onset GBS infection rate was 0.58 per 1000 live births and mortality was 0.29 per 1000 live births. Age younger than 40 years $(p=0.040)$ and minority ethnic status $(p=0.049)$ were associated with higher GBS colonization rate in pregnant women. Positive GBS status in the mother prior to delivery $(p<0.001)$ as well as longer duration of membrane rupture $(\geq 12 h)(p<0.001)$ and longer labor $(\geq 4 h)(p<0.001)$ were all significant risk factors for GBS colonization in infants. Compared to infants without GBS colonization, infants colonized with GBS were more likely to have had a temperature of $\geq 38^{\circ} \mathrm{C}(p<0.001)$, developed early onset infection (EOD) $(p<0.001)$, and been prescribed antibiotics $(p<0.001)$. Furthermore, infants with GBS were more likely to have been admitted to neonatal intensive unit (NICU) $(p<0.001)$ with a longer hospital length of stay (LOS) $(p<0.001)$.

Conclusions: Maternal GBS colonization, longer duration of membrane rupture and labor were all major risk factors associated with GBS colonization in Chinese infants. Infant GBS colonization was associated with increased risk of EOD and NICU admission as well as longer LOS.
\end{abstract}

Keywords: Group B streptococcus, GBS colonization, Early onset disease (EOD), Mother-infant pairs

\section{Background}

Streptococcus agalactiae, known as Group B streptococcus (GBS), is a common colonizing pathogen in pregnant women that can cause invasive infections during peripartum period [1]. The Vaginal and rectal tract are considered major reservoirs of GBS [2]. Mucosa surfaces such as oral, nasopharyngeal, vaginal and anal mucosa

\footnotetext{
* Correspondence: emcgrath@med.wayne.edu

${ }^{\dagger}$ Jichang Chen and Jinjian Fu contributed equally to this work.

${ }^{3}$ Children's Hospital of Michigan, Detroit, MI, USA

${ }^{4}$ Department of Pediatrics, Wayne State University School of Medicine, Detroit, MI, USA

Full list of author information is available at the end of the article
}

and skin of newborns at birth support the colonization of GBS [3]. It was reported that the risk of colonization of GBS was much higher in infants who were born to GBS positive mothers, and the likelihood was even higher if the mother was heavily colonized (growth of GBS with a density between $3^{+}$to $4^{+}$) [4,5]. GBS can easily be transmitted vertically from mothers to newborns in the peripartum period, especially during vaginal delivery [6]. GBS has been the principal cause of septicemia, meningitis and pneumonia for early and late onset diseases in newborns and was attributed to infant mortality in many parts of the world [4]. Little is known

(C) The Author(s). 2018 Open Access This article is distributed under the terms of the Creative Commons Attribution 4.0 International License (http://creativecommons.org/licenses/by/4.0/), which permits unrestricted use, distribution, and 
about the burden of perinatal GBS colonization and related infections in China. Specifically, the prevalence of maternal and infant GBS colonization and the risk factors for vertical transmission of GBS from mothers to infants have not been reported in western China. Since there is no screening for GBS or intrapartum administration of antibiotics (IAP) protocol was in place in China for prevention of GBS disease at the time of this study, the aims of this study were to determine the prevalence of and risk factors for maternal and infant GBS colonization at Liuzhou Maternity and Child Healthcare Hospital (LMCHH), one of the largest maternal and child health care hospitals in Guangxi in western China, in order to inform future prevention efforts and interventions.

\section{Methods}

\section{Study design}

This was a prospective mother-infant pair study conducted between January 2017 and June 2017 at LMCHH in Liuzhou, Guanxi Province in western China. This study recruited mother-infant pairs from $\mathrm{LMCHH}$ during the study period. The study included pregnant women ( $\geq 35$ weeks of gestation) visiting the antenatal clinic for routine prenatal care and those who were approached at time of delivery. If no sample was collected during these routine prenatal visits, then they would be swabbed at the time of delivery.

The exclusion criteria included: (1) all twins or multiple births (2) in any case where GBS culture results were not obtainable; and (3) the screened pregnant woman delivered outside LMCHH. An oral consent was obtained from participating women and the study was approved by the Institutional Review Board at LMCHH.

GBS screening was per protocol as part of this study's procedures. No routine screening for GBS or intrapartum administration of antibiotics (IAP) protocol were in place in China at the time of this study. If pregnant women had additional clinical risk factors such as fever and/or preterm birth, then antibiotics may have been given at the discretion of the treating clinician, but there was no formal IAP protocol which was followed.

\section{Data collection}

Women and newborns were followed during the entire delivery hospitalization in LMCHH. The microbiological, clinical records and hospital databases were reviewed and recorded at the end follow-up for each pair of participants. Demographics, microbiological and clinical records from hospital databases were reviewed and extracted by study investigators in $\mathrm{LMCHH}$. Data elements included in this study were: maternal age, previous obstetric history, gestational age, parity, mode of delivery, duration of membrane rupture (in hours), labor duration (in hours), antibiotic use of mother and newborn, newborn gender, birth weight, neonatal fever, newborn length of stay (LOS), occurrence of early onset diseases (EOD), and neonatal intensive care unit (NICU) admission.

\section{Definition}

Fever [7]: A temperature of $\geq 38{ }^{\circ} \mathrm{C}$ in newborns was considered as the threshold for fever.

Early Onset Disease (EOD) [5]: A diagnosis by way of isolation of bacteria from sterile sites such as blood or CSF within 7 days after birth.

Prolonged rupture of membranes [8]: Membrane rupture of $\geq 12 \mathrm{~h}$ was considered as the threshold for prolonged rupture of membranes.

Prolonged labor: Since there was no standard definition of prolonged labor, labor duration of $\geq 4 \mathrm{~h}$ was used as the cut-off value of prolonged duration of labor for this study.

Minority ethnic group: There are 56 different ethnic groups in China. Han and Zhuang are the two major ethnic groups in Guangxi, which consist of about $90 \%$ of the population in Guangxi. The minority ethnic group is defined as any other ethnic groups except Han and Zhuang.

\section{Specimen collection and microbiologic methods}

Vaginal and rectal swabs as two different swabs were collected from pregnant women for bacterial cultures at 35-37 weeks of gestation by their obstetrical/gynecological physician. If the bacterial culture was not done at around 35-37 weeks, vaginal and rectal swabs were collected at the onset of labor. One sample swab from newborns was collected by the treating perinatologist in the order of nasopharynx, then ear canal and final umbilical cord. Swabs were collected from newborns immediately after birth (< one hour).

Specimens were collected using sterile swabs then placed in Stuart transport medium and sent to laboratory within $2 \mathrm{~h}$ of obtaining the samples. The swabs were incubated in a selective enrichment broth medium (Todd Hewitt broth) (OXOID, England) containing nalidixic acid $(15 \mathrm{mg} / \mathrm{L})$ and gentamicin $(8 \mathrm{mg} / \mathrm{L})$ at $37^{\circ} \mathrm{C}$ for $18-24 \mathrm{~h}$. The broths were sub-cultured in Columbia 5\% sheep blood agar (Autobio, China) and incubated at $37{ }^{\circ} \mathrm{C}$ in $5 \% \mathrm{CO}_{2}$ for 18 to $24 \mathrm{~h}$. Colonies were identified presumptively by colony morphology, Gram stain, catalase reaction, hemolytic activity on sheep blood agar plates, Hippurate and CAMP test. The suspected colonies were further tested with Gram positive bacteria identification card using VITEK 2 compact automatic microbial analysis system (Biomérieux, Marcyl' Etoile, France) to confirm GBS isolates.

\section{Statistical analysis}

SAS version 9.4 (Cary, NC, USA) was used to perform the statistical analysis. Continuous variables were analyzed 
using 2-sample $t$-tests. Categorical variables were analyzed and compared by chi-square or Fisher's exact tests. Odds ratios (ORs) and their 95\% confidence intervals (CIs) were calculated to assess the relative risk associated with maternal and infant GBS colonization. Multivariate logistic regression in conjunction with Stepwise backward elimination model selection method was performed to evaluate the relative strength of potential risk factors for GBS colonization in mothers and infants separately. A $p$-value less than 0.05 was considered indicative of statistical significance.

\section{Results}

\section{Enrollment}

Data from 4140 births were collected and recorded during the study period (see Fig. 1). Seven hundred and one were excluded. This left a total of 3439 births that were eligible to be included in the study.

\section{Maternal data}

Among the 3439 specimens from mothers, 2841 were obtained during their routine prenatal visits while 598 specimens were collected at the onset of labor. Among 3439 women, GBS was isolated in 210 , and the overall colonization rate was $6.1 \%$. Table 1 examined the characteristics of mothers as potential risk factors for GBS colonization. A multivariate analysis has found that age younger than 40 years $(P=0.040)$ as well as being in the minority ethnic group $(p=0.049)$ were significant risk factors for GBS colonization (Table 2).
Risk factors and outcomes for infants GBS colonization Of the 3439 infants in the study, 377 (10.9\%) were born prematurely (<37 weeks' gestation). There were two cases of culture-proven GBS positive EOD: one from blood and the other from the cerebrospinal fluid. Four other cases were positive for other pathogens (two were Escherichia coli, one was Candida albicans and the other was Staphylococcus aureus) from blood cultures. One infant died during delivery with GBS infection revealed by growth of the pathogen from a blood culture obtained upon delivery. The EOD incidence from GBS was 0.58 per 1000 live births while the infant mortality rate of GBS was 0.29 per 1000 live births.

Twenty-three of the 3439 neonatal samples were positive for growth of GBS, with an estimated colonization rate of $0.7 \%$. Among the 210 mothers who were positive for GBS by culture, only 16 of their infants were GBS positive, resulting in a $7.6 \%$ vertical transmission rate.

Table 3 shows the association between characteristics of mothers at labor and infant GBS colonization in univariate analysis. GBS colonization in mother $(p<0.001)$, episiotomy $(p=0.020)$, vaginal birth $(p=0.027)$, longer duration of membrane rupture $(\geq 12 \mathrm{~h})(p<0.001)$, and longer labor $(\geq 4 \mathrm{~h})(p<0.001)$ were all significantly associated with GBS colonization in newborns. In multivariate analysis, only maternal GBS colonization $(p<$ $0.001)$, duration of membrane rupture $\geq 18 \mathrm{~h}(p<0.001)$ and length of labor $\geq 4 \mathrm{~h}(p<0.001)$ were included in

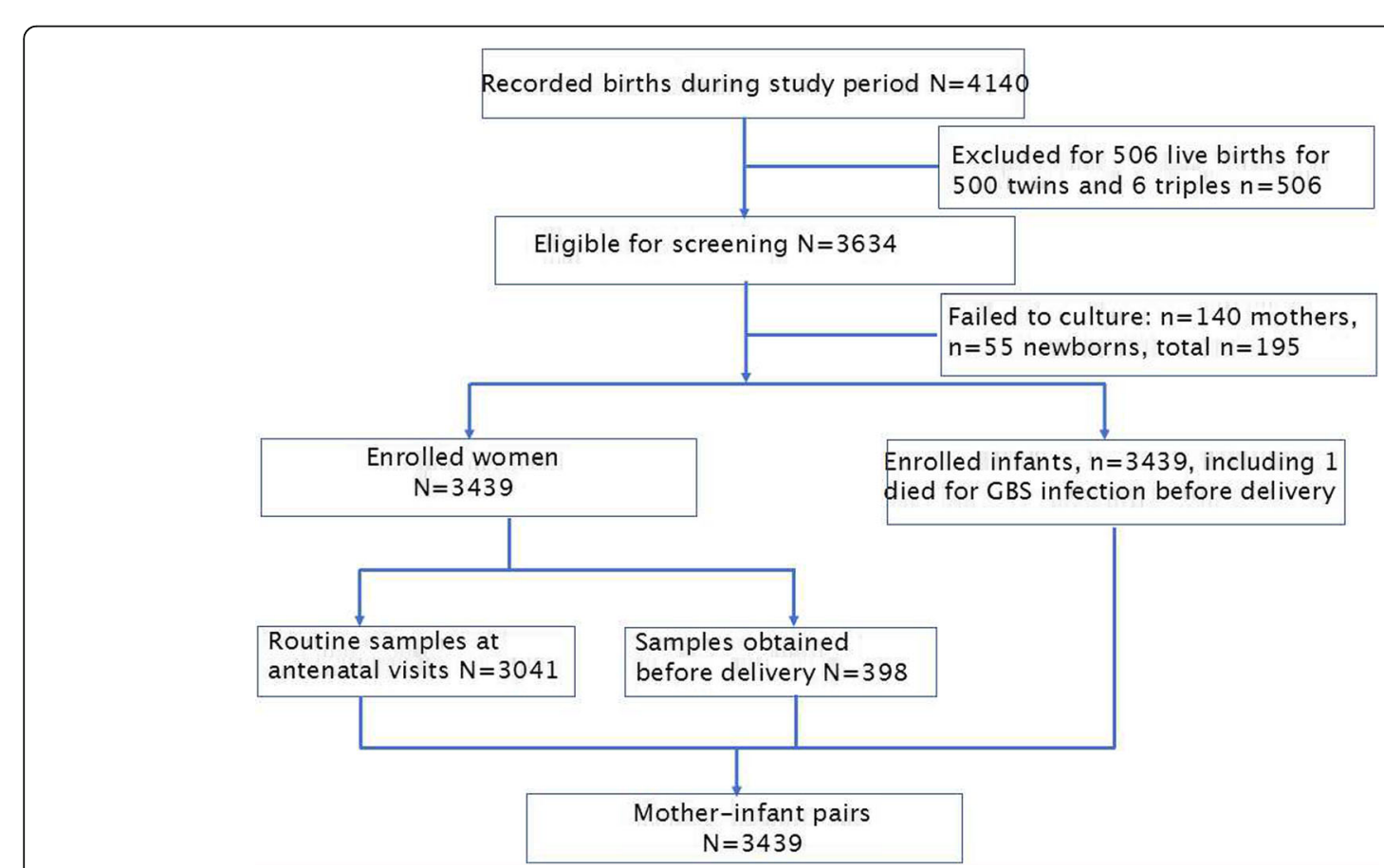

Fig. 1 Enrollment flow chart 
Table 1 Association between risk factors and GBS colonization among pregnant women

\begin{tabular}{|c|c|c|c|c|}
\hline Variables & GBS carriers $(n=210)(n, \%)$ & GBS negative $(n=3229)(n, \%)$ & $\mathrm{OR}(95 \% \mathrm{Cl})$ & $P$ value \\
\hline Maternal age (years) & & & & 0.040 \\
\hline $18-39$ & 207(98.6) & 3080(95.4) & $3.33(1.05-11.1)$ & \\
\hline$\geq 40^{\mathrm{a}}$ & $3(1.4)$ & $149(4.6)$ & & \\
\hline Ethnic & & & & 0.048 \\
\hline Han-Zhuang ${ }^{a}$ & 190(90.5) & 3033(93.9) & & \\
\hline Minority & $20(9.5)$ & 196(6.1) & $1.63(1.01-2.64)$ & \\
\hline \multicolumn{5}{|l|}{ Education level } \\
\hline$\leq 9$ years of school ${ }^{a}$ & $91(43.3)$ & $1422(44.0)$ & & \\
\hline 10-12 years of school & 67(31.9) & 1116(34.6) & $0.94(0.68-1.30)$ & 0.700 \\
\hline$\geq 13$ years of school & $52(24.8)$ & $69(21.4)$ & 1.18(0.83-1.67) & \\
\hline \multicolumn{5}{|l|}{ Current smoking } \\
\hline $\mathrm{No}^{\mathrm{a}}$ & 209(99.5) & 3195(98.9) & & \\
\hline Yes & $1(0.5)$ & $34(1.1)$ & $0.45(0.06-3.30)$ & 0.432 \\
\hline \multicolumn{5}{|l|}{ Previous miscarriage } \\
\hline $\mathrm{No}^{\mathrm{a}}$ & 195(92.9) & 2942(91.1) & & \\
\hline Yes & $15(7.1)$ & $287(8.9)$ & $0.79(0.46-1.35)$ & 0.388 \\
\hline \multicolumn{5}{|c|}{ Pregnancy-induced hypertension } \\
\hline $\mathrm{No}^{\mathrm{a}}$ & 197(93.8) & 3078(95.3) & & \\
\hline Yes & $13(6.2)$ & $151(4.7)$ & $1.35(0.75-2.41)$ & 0.320 \\
\hline \multicolumn{5}{|l|}{ Gestational diabetes } \\
\hline $\mathrm{No}^{\mathrm{a}}$ & 159(75.7) & $2397(74.2)$ & & \\
\hline Yes & $51(24.3)$ & $832(25.8)$ & $0.92(0.67-1.28)$ & 0.634 \\
\hline \multicolumn{5}{|l|}{ Parity } \\
\hline $1-2^{a}$ & 205(97.6) & 3088(95.6) & & \\
\hline$\geq 3$ & $5(2.4)$ & $141(4.4)$ & $0.53(0.22-1.32)$ & 0.174 \\
\hline \multicolumn{5}{|c|}{ Maternal previous antibiotic use } \\
\hline $\mathrm{No}^{\mathrm{a}}$ & 208(99.0) & $3131(97.0)$ & & \\
\hline Yes & $2(1.0)$ & $98(3.0)$ & $0.31(0.07-1.26)$ & 0.100 \\
\hline
\end{tabular}

OR odds ratio, $95 \% \mathrm{Cl} 95 \%$ confidence interval

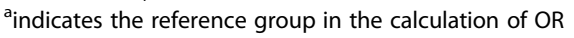

the final model predicting risk of GBS colonization in infants (Table 4).

Infants colonized with GBS were more likely to have had a temperature of $\geq 38{ }^{\circ} \mathrm{C}(p<0.001)$, developed EOD $(p<0.001)$, and received antibiotics $(p<0.001)$ (Table 5). Infants with GBS were also more likely to have been admitted to the NICU $(p<0.001)$ with a longer hospital LOS (11 vs. 3 days; $p<0.001)$.

Table 2 Multivariate logistic regression analysis of risk factors associated with GBS colonization among pregnant women

\begin{tabular}{llll}
\hline Variables & OR & $95 \% \mathrm{Cl}$ & $p$ value \\
\hline Maternal age $\left(\geq 40\right.$ yrs. vs. $<40$ yrs $^{\mathrm{a}}$ ) & 0.30 & $0.09-0.95$ & 0.040 \\
Ethnicity (minority vs. Han-Zhuang ${ }^{\mathrm{a}}$ ) & 1.62 & $1.00-2.63$ & 0.049
\end{tabular}

OR odds ratio, $95 \% \mathrm{Cl} 95 \%$ confidence interval

${ }^{a}$ indicates the reference group in the calculation of $O R$

\section{Discussion}

Our study demonstrates that the GBS colonization rate in pregnant Chinese women in Liuzhou was 6.1\%, which is similar to the reported rate of $7.1 \%$ in Beijing [9] and 8.2\% in Dongguan [10]. Our rate is similar to those of other Asian countries including Philippines (7.5\%) [11], Japan (8.2\%) [12], Myanmar (7.1\%) [11] and South Korea $(8.0 \%)$ [13]. but lower than the global colonization rate of $17.9 \%$ reported by a recent meta-analysis study [14]. The GBS colonization rate in our study was also lower than the rate reported in Southeast Asia (11.1\%) [14]. These results indicate that GBS colonization prevalence in pregnant women varies widely across the globe. Factors that may have contributed to this variation include the level of economic development, the availability of medical care and preventive services, varying clinical 
Table 3 Association between maternal characteristics and potential risk factors for neonatal GBS colonization

\begin{tabular}{|c|c|c|c|c|}
\hline Variables & GBS colonization $(n=23)(n, \%)$ & GBS negative $(n=3416)(n, \%)$ & $\mathrm{OR}(95 \% \mathrm{Cl})$ & $P$ value \\
\hline \multicolumn{5}{|l|}{ Maternal age (years) } \\
\hline $18-39$ & $23(100.0)$ & 3264(95.6) & $0.00(0.00-0.00)$ & 0.996 \\
\hline$\geq 40^{\mathrm{a}}$ & $0(0.0)$ & $152(4.4)$ & & \\
\hline \multicolumn{5}{|l|}{ Ethnic } \\
\hline Han-Zhuang ${ }^{\text {a }}$ & $22(95.7)$ & $3201(93.7)$ & & \\
\hline Minority & $1(4.3)$ & 215(6.3) & $0.68(0.09-5.05)$ & 0.703 \\
\hline \multicolumn{5}{|l|}{ Education level } \\
\hline$\leq 9$ years of school ${ }^{a}$ & $9(39.1)$ & 1504(44.0) & & \\
\hline 10-12 years of school & $10(43.5)$ & 1173(34.3) & $1.43(0.58-3.52)$ & 0.443 \\
\hline$\geq 13$ years of school & $4(17.4)$ & $739(21.6)$ & $0.91(0.28-2.95)$ & 0.868 \\
\hline \multicolumn{5}{|l|}{ Current smoking } \\
\hline $\mathrm{No}^{\mathrm{a}}$ & $23(100.0)$ & $3381(99.0)$ & & \\
\hline Yes & $0(0.0)$ & $35(1.0)$ & $0.00(0.0-0.0)$ & 0.998 \\
\hline \multicolumn{5}{|l|}{ Previous miscarriage } \\
\hline $\mathrm{No}^{\mathrm{a}}$ & $23(100.0)$ & $3114(91.2)$ & & \\
\hline Yes & $0(0.0)$ & $302(8.8)$ & $0.00(0.0-0.0)$ & 0.998 \\
\hline \multicolumn{5}{|c|}{ Pregnancy-induced hypertension } \\
\hline $\mathrm{No}^{\mathrm{a}}$ & 31(91.3) & $3254(95.3)$ & & \\
\hline Yes & $2(8.7)$ & $162(4.7)$ & $1.91(0.45-8.23)$ & 0.384 \\
\hline \multicolumn{5}{|l|}{ Gestational diabetes } \\
\hline $\mathrm{No}^{\mathrm{a}}$ & 20(87.0) & $2536(74.2)$ & & \\
\hline Yes & $3(13.0)$ & $880(25.8)$ & $0.43(0.13-1.46)$ & 0.176 \\
\hline \multicolumn{5}{|l|}{ Parity } \\
\hline $1-2^{a}$ & $23(100.0)$ & $3270(95.7)$ & & \\
\hline$\geq 3$ & $0(0.0)$ & $146(4.3)$ & $0.00(0.0-0.0)$ & 0.996 \\
\hline \multicolumn{5}{|l|}{ Cesarean section } \\
\hline $\mathrm{No}^{\mathrm{a}}$ & 18(78.3) & $1844(54.0)$ & & \\
\hline Yes & $5(21.7)$ & $1572(46.0)$ & $0.33(0.12-0.88)$ & 0.027 \\
\hline \multicolumn{5}{|l|}{ Episiotomy } \\
\hline $\mathrm{No}^{\mathrm{a}}$ & $14(60.9)$ & $2764(80.9)$ & & \\
\hline Yes & $9(39.1)$ & $652(19.1)$ & $2.73(1.17-6.32)$ & 0.020 \\
\hline \multicolumn{5}{|l|}{ Membrane rupture } \\
\hline$<11$ hours $^{a}$ & $15(65.2)$ & 3376(98.8) & & \\
\hline$\geq 12 \mathrm{~h}$ & $8(34.8)$ & $40(1.2)$ & $45.01(18.06-112.16)$ & $<0.001$ \\
\hline \multicolumn{5}{|l|}{ Length of labor } \\
\hline$<4$ hours $^{a}$ & $11(47.8)$ & $3165(92.7)$ & & \\
\hline$\geq 4$ hours & $12(52.2)$ & $251(7.3)$ & 13.75(6.01-31.48) & $<0.001$ \\
\hline \multicolumn{5}{|c|}{ Maternal previous antibiotic use } \\
\hline $\mathrm{No}^{\mathrm{a}}$ & 23(100.0) & $3316(97.1)$ & & \\
\hline Yes & $0(0.0)$ & 100(2.9) & $0.00(0.0-0.0)$ & 0.997 \\
\hline \multicolumn{5}{|l|}{ Gestational age } \\
\hline Full-term $\geq 37$ weeks $^{a}$ & 21(91.3) & $3041(89.0)$ & & \\
\hline Preterm $<37$ weeks & $2(8.7)$ & $375(11.0)$ & $0.77(0.18-3.31)$ & 0.728 \\
\hline
\end{tabular}


Table 3 Association between maternal characteristics and potential risk factors for neonatal GBS colonization (Continued)

\begin{tabular}{|c|c|c|c|c|}
\hline Variables & GBS colonization $(n=23)(n, \%)$ & GBS negative $(n=3416)(n, \%)$ & $\mathrm{OR}(95 \% \mathrm{Cl})$ & $P$ value \\
\hline \multicolumn{5}{|c|}{ Maternal GBS colonization } \\
\hline $\mathrm{No}^{\mathrm{a}}$ & $7(30.4)$ & $3222(94.3)$ & & \\
\hline Yes & 16(69.6) & 194(5.7) & 37.96(15.44-93.36) & $<0.001$ \\
\hline
\end{tabular}

OR odds ratio, $95 \% \mathrm{Cl} 95 \%$ confidence interval

${ }^{a}$ indicates the reference group in the calculation of OR

practice guidelines, as well as differing average child bearing age [15]. Our study found that ethnic minority pregnant women in Liuzhou were significantly more likely to be colonized with GBS when compared with Han and Zhuang ethnic groups. This is consistent with the previous study conducted in US which showed higher GBS colonization rates were more likely to have black and Hispanic maternal races than white race [16-19].

In the present study, we found that there was a significant association between maternal GBS colonization and newborn GBS colonization. Studies have found that the risk factors for infant GBS colonization include maternal rectovaginal colonization, preterm delivery, low birth weight, antepartum and intrapartum fever and prolonged membrane rupture [20-22]. Although we found no association between maternal GBS colonization and preterm birth, we did find the association between both membrane rupture $(\geq 12 \mathrm{~h})$ duration and labor duration $(\geq 4 \mathrm{~h})$ with infant GBS colonization risk. Our data was consistent with a previous study conducted in China which showed that prolonged rupture of membranes and increased duration of rupture of membranes were significant risk factors for neonatal GBS colonization [23].

Our data show that vertical transmission from mothers to their newborns was $7.6 \%$. This is lower than what was reported in Europe and Asia, which have a transmission rate of $11.2 \%$ in Germany [24], 15.1\% in Bangladesh [25] and $16.7 \%$ in Taiwan [26]. It is known that birth canal contact is a risk factor of GBS transmission to newborns [27]. The cesarean section rate at $\mathrm{LMCHH}$ was $54.1 \%$, while the cesarean section rate was $42 \%$ in mainland China [28]. The high cesarean section rate may explain in part the low rate of vertical transmission in our study. It is also worth noting that despite the implementation of a universal protocol of GBS screening procedures in our institution, we still observed 7 infants with GBS colonization who were born to GBS-negative mothers. It was reported

Table 4 Multivariate logistic regression analysis of risk factors associated with GBS colonization among infants

\begin{tabular}{|c|c|c|c|}
\hline Variables & OR & $95 \% \mathrm{Cl}$ & $P$ value \\
\hline Membrane rupture ( $\geq 12$ h vs. $<12$ hrs $^{a}$ ) & 125.75 & $30.72-514.76$ & $<0.001$ \\
\hline Length of labor ( $\geq 4$ h vs. $<4$ hrs $^{\mathrm{a}}$ ) & 10.64 & $3.16-35.86$ & $<0.001$ \\
\hline Maternal GBS colonization (yes vs. no ${ }^{\mathrm{a}}$ ) & 21.52 & $7.03-65.85$ & 0.001 \\
\hline
\end{tabular}

OR odds ratio, $95 \% \mathrm{Cl} 95 \%$ confidence interval

${ }^{a}$ indicates the reference group in the calculation of $O R$ that false negative results are expected to occur based on several procedure of the implementation of screening test for GBS [16]. Improper collection methods, delay in processing, insufficient laboratory techniques, recent antibiotic use, or delay in GBS colonization may all have contributed to the negative GBS screening results in mothers who deliver GBS positive infants [18, 29, 30]. Several studies have examined the risk of GBS colonization in infants who were born to GBS negative mothers. The reported rates by these studies, ranged between 21.5 and $61.4 \%$, [16, 31, 32] were consistent with our study observed rate of $30.4 \%(7 / 23)$. To improve the accuracy of screening by identifying the GBS status, a rapid polymerase chain reaction (PCR) test could be used at the time of labor to increase the sensitivity and specificity of the tests [33-35].

Our data demonstrated that GBS colonization remains an important cause of infant morbidity requiring NICU admission and longer LOS. Clinically, infants may be colonized with GBS through intra-amniotic infection by way of GBS ascending from the vagina or through birth canal contact during labor [27]. Exposure to GBS increased the

Table 5 Neonatal GBS colonization outcomes

\begin{tabular}{|c|c|c|c|}
\hline Variables & $\begin{array}{l}\text { GBS colonization } \\
(n=23)(n, \%)\end{array}$ & $\begin{array}{l}\text { GBS negative } \\
(n=3416)(n, \%)\end{array}$ & $P$ value \\
\hline Gender & & & 0.122 \\
\hline Male & 16(69.6) & 1813(53.1) & \\
\hline Female & $7(30.4)$ & 1603(46.9) & \\
\hline Birth weight, gram & $3126 \pm 52$ & $2895 \pm 55$ & 0.036 \\
\hline Neonatal fever & & & $<0.001$ \\
\hline No & $20(87.0)$ & 3412(99.9) & \\
\hline Yes & $3(13.0)$ & $4(0.1)$ & \\
\hline Neonatal antibiotic use & & & $<0.001$ \\
\hline No & 19(82.6) & 3412(99.9) & \\
\hline Yes & $4(17.4)$ & $4(0.1)$ & \\
\hline Transferred to NICU & & & $<0.001$ \\
\hline No & 15(65.2) & 3413(99.9) & \\
\hline Yes & $8(34.8)$ & $3(0.1)$ & \\
\hline $\begin{array}{l}\text { Length of stay (days) } \\
\text { Mean (range) }\end{array}$ & $10.9(4-34)$ & $3.1(2-18)$ & $<0.001$ \\
\hline Occurrence of EOD & & & $<0.001$ \\
\hline No & 21(91.3) & 3412(99.9) & \\
\hline Yes & $2(8.7)$ & $4(0.1)$ & \\
\hline
\end{tabular}

NICU neonatal intensive care unit; EOD early onset diseases 
risk of GBS-EOD, which often leads to NICU admission [26]. A previous study indicated that infants born to GBS positive mothers were at a higher risk of admission to the NICU [36], which is consistent with our study findings. Possible reasons for the increased morbidity of GBS positive infants include exposure to GBS in the perinatal period [27], hypervirulence of certain GBS strains [37], as well as the "maternal antibody" hypothesis [38]. The serotype III of GBS is considered hypervirulent which may cause a longer colonization duration throughout the pregnancy and is the most common serotype isolated in neonates less than 7 days of age [21]. In addition, maternal serum IgG antibodies against specific capsular polysaccharides of GBS has been shown to be protective against infection with virulence strain of GBS in their offspring [31]. Mothers with low titers of IgG antibodies against the GBS strains may be responsible for the hypervirulence of GBS [38], thus contributing to the GBS colonization and possible future infection in their newborns.

This study possessed two strengths. This is the first large-scale study conducted in western China with a cohort consisting of 3439 pairs of mothers and infants. Additionally, we collected surface culture on all newborns regardless of maternal GBS culture results.

There are some limitations to our study. First of all, the single-center design and the low prevalence of GBS positive infants may limit the generalizability of our study results. Secondly, the incidence of GBS-EOD may have been underestimated because we did not follow the infants who were discharged from hospital before 7 days. Lastly, due to budget constraints, the study utilized a culture-based testing procedure which is less expensive but not as sensitive as the PCR test.

\section{Conclusions}

Our study revealed that maternal age as well as ethnicity may play a role in maternal colonization of GBS. Maternal colonization with GBS, longer duration of membrane rupture and labor were significant risk factors for GBS colonization in Chinese newborns. Outcomes of infants colonized with GBS included fever, increased need for antibiotic, NICU admission as well as longer LOS. Future studies are needed to establish guidelines for GBS screening and Intrapartum Antibiotic Prophylaxis use in China. Prospective studies are also needed to evaluate the GBS disease burden in Chinese mothers and infants nationwide.

\footnotetext{
Abbreviations

95\%Cl: 95\% confidence interval; EOD: Early onset diseases; GBS: Group b streptococcus; IAP: Intrapartum antibiotic prophylaxis; NICU: Neonatal intensive care unit; OR: Odds ratio
}

\section{Funding}

This manuscript was funded by Guangxi Medical and Health Self-funding Project (No Z2015188 and No Z20170543). The funders had no role in study design, data collection and analysis, decision to publish, or preparation of the manuscript.

Availability of data and materials

We declare that the data supporting the conclusions of this article are fully described within the article, and the database is available from the first author (cjclzsfy@126.com) upon reasonable request.

\section{Authors' contributions}

JC and JF designed the study and drafted an outline. WD and JF participated in data analysis, JF drafted initial manuscript, WD and EM critically revised the initial manuscript and EM directed additional data analysis, $\mathrm{XL}, \mathrm{XH}, \mathrm{YBW}$ and YLW participated in diagnosis of patients and data collection, EM, WD, and CR critically revised the final manuscript and all of authors approved the final content off this manuscript.

\section{Ethics approval and consent to participate}

This study was approved by the Institutional Review Board of Liuzhou Maternity and Child Healthcare Hospital. An oral consent was obtained from participating women, and demographics (omitted the participants and their infants' name), microbiological and clinical records were collected according to the verbal consent procedure. The verbal consent procedure was approved by the Institutional Review Board at $\mathrm{LMCHH}$.

Consent for publication

Not applicable.

Competing interests

The authors declare that they have no competing interests.

\section{Publisher's Note}

Springer Nature remains neutral with regard to jurisdictional claims in published maps and institutional affiliations.

\section{Author details}

${ }^{1}$ Department of Neonatology, Liuzhou Maternity and Child Health Care Hospital, Liuzhou 545001, China. 'Department of Laboratory, Liuzhou Maternity and Child Healthcare Hospital, Liuzhou 545001, China. ${ }^{3}$ Children's Hospital of Michigan, Detroit, MI, USA. ${ }^{4}$ Department of Pediatrics, Wayne State University School of Medicine, Detroit, MI, USA. ${ }^{5}$ Department of Pediatrics, Liuzhou Maternity and Child Healthcare Hospital, Liuzhou 545001, China. ${ }^{6}$ Department of Infectious Diseases, Valley Children's Hospital, Madera, CA, USA. 7 Department of Obstetrics and Gynecology, Liuzhou Maternity and Child Healthcare Hospital, Liuzhou 545001, China. ${ }^{8}$ Division of Infectious Diseases, Children's Hospital of Michigan, 3901 Beaubien Boulevard, Detroit, MI 48201, USA.

Received: 18 December 2017 Accepted: 26 June 2018

Published online: 03 July 2018

\section{References}

1. Pérez-Moreno MO, Picó-Plana E, Grande-Armas J, Centelles-Serrano MJ, et al. Group B streptococcal bacteriuria during pregnancy as a risk factor for maternal intrapartum colonization: a prospective cohort study. J Med Microbiol. 2017;66(4):454-60. https://doi.org/10.1099/jmm.0.000465.

2. El Aila NA, Tency I, Claeys G, Saerens B, et al. Comparison of different sampling techniques and of different culture methods for detection of group B streptococcus carriage in pregnant women. BMC Infect Dis. 2010 Sep 29;10:285. https://doi.org/10.1186/1471-2334-10-285

3. Schuchat A, Wenger JD. Epidemiology of group B streptococcal disease. Risk factors, prevention strategies, and vaccine development. Epidemiol Rev. 1994;16(2):374-402.

4. Le Doare K, Heath PT. An overview of global GBS epidemiology. Vaccine. 2013;31(Suppl 4):D7-12. https://doi.org/10.1016/j.vaccine.2013.01.009.

5. Berardi A, Rossi C, Guidotti I, Vellani G, et al. Factors associated with intrapartum transmission of group B Streptococcus. Pediatr Infect Dis J. 2014;33(12):1211-5. https://doi.org/10.1097/INF.0000000000000439.

6. Centers for Disease Control and Prevention. Prevention of perinatal group B streptococcal disease: revised guidelines from the CDC. MMWR. 2002;51:1-22. 
7. Puopolo KM, Draper D, Wi S, Newman TB, et al. Estimating the probability of neonatal early-onset infection on the basis of maternal risk factors. Pediatrics. 2011;128(5):e1155-63. https://doi.org/10.1542/peds.2010-3464.

8. Boyer KM, Gotoff SP. Strategies for chemoprophylaxis of GBS early-onset infections. Antibiot Chemother (1971). 1985;35:267-80.

9. Lu B, Li D, Cui Y, Sui W, et al. Epidemiology of group B streptococcus isolated from pregnant women in Beijing, China. Clin Microbiol Infect. 2014; 20(6):O370-3. https://doi.org/10.1111/1469-0691.12416.

10. Ji W, Zhang L, Guo Z, Xie S, et al. Colonization prevalence and antibiotic susceptibility of group B Streptococcus in pregnant women over a 6-year period in Dongguan, China. PLoS One. 2017;12(8):e0183083. https://doi.org/ 10.1371/journal.pone.0183083.

11. Whitney CG, Daly S, Limpongsanurak S, Festin MR, et al. Global network for perinatal and reproductive health. The international infections in pregnancy study: group B streptococcal colonization in pregnant women. J Matern Fetal Neonatal Med. 2004;15(4):267-74.

12. K M, Katayama K, Baba K, Nigami H, et al. Seroepidemiologic studies of serotype VIII group B Streptococcus in Japan. J Infect Dis. 2002;186(6):855-8.

13. Lee BK, Song YR, Kim MY, Yang JH, et al. Epidemiology of group B streptococcus in Korean pregnant women. Epidemiol Infect. 2010;138(2): 292-8. https://doi.org/10.1017/\$0950268809990859.

14. Kwatra G, Cunnington MC, Merrall E, Adrian PV, et al. Prevalence of maternal colonisation with group B streptococcus: a systematic review and metaanalysis. Lancet Infect Dis. 2016;16(9):1076-84. https://doi.org/10.1016/ S1473-3099(16)30055-X.

15. Rick AM, Aguilar A, Cortes R, Gordillo R, et al. Group B streptococci colonization in pregnant Guatemalan women: prevalence, risk factors, and vaginal microbiome. Open Forum Infect Dis. 2017;4(1):ofx020. https://doi. org/10.1093/ofid/ofx020.

16. Van Dyke MK, Phares CR, Lynfield R, Thomas AR, et al. Evaluation of universal antenatal screening for group B streptococcus. N Engl J Med. 2009;360(25):2626-36. https://doi.org/10.1056/NEJMoa0806820.

17. Taylor JK, Hall RW, Dupre AR. The incidence of group B streptococcus in the vaginal tracts of pregnant women in Central Alabama. Clin Lab Sci. 2002; 15(1):16-7.

18. Parente V, Clark RH, Ku L, Fennell C, et al. Risk factors for group B streptococcal disease in neonates of mothers with negative antenatal testing. J Perinatol. 2017;37(2):157-61. https://doi.org/10.1038/jp.2016.201.

19. Kessous R, Weintraub AY, Sergienko R, Lazer T, et al. Bacteruria with group-B streptococcus: is it a risk factor for adverse pregnancy outcomes? J Matern Fetal Neonatal Med. 2012;25(10):1983-6. https://doi.org/10.3109/14767058. 2012.671872.

20. Müller-Vranjes A, Puntarić D, Curzik D, Sijanović S, et al. Prevalence and significance of vaginal group B streptococcus colonization in pregnant women from Osijek. Croatia Coll Antropol. 2011;35(1):21-6.

21. Seoud M, Nassar AH, Zalloua P, Boghossian N, Ezeddine J, Fakhoury H, Abboud J, Melki I, Araj G, Nacouzi G, Sanyoura M, Yunis K. Prenatal and neonatal group B Streptococcus screening and serotyping in Lebanon: incidence and implications. Acta Obstet Gynecol Scand. 2010;89(3):399-403.

22. Werawatakul Y, Wilailuckana C, Taksaphan S, Thinkumrup J, et al. Prevalence and risk factors of Streptococcus agalactiae (group B) colonization in mothers and neonatal contamination at Srinagarind hospital. J Med Assoc Thail. 2001;84(10):1422-9.

23. Liang ST, Lau SP, Chan SH, Fok TF, Murai T, Kaneko Y. Perinatal colonization of group B streptococcus-an epidemiological study in a Chinese population. Aust N Z J Obstet Gynaecol. 1986;26(2):138-41.

24. Kunze $M$, Ziegler $A$, Fluegge $K$, Hentschel $R$, et al. Colonization, serotypes and transmission rates of group B streptococci in pregnant women and their infants born at a single University Center in Germany. J Perinat Med. 2011;39(4):417-22. https://doi.org/10.1515/JPM.2011.037.

25. Saha SK, Ahmed ZB, Modak JK, Naziat H, et al. Group B Streptococcus among pregnant women and newborns in Mirzapur, Bangladesh: colonization, vertical transmission, and serotype distribution. J Clin Microbiol. 2017;55(8):2406-12. https://doi.org/10.1128/JCM.00380-17.

26. Yang MJ, Sun PL, Wen KC, Chao KC, et al. Prevalence of maternal group $B$ streptococcus colonization and vertical transmission in low-risk women in a single institute. J Chin Med Assoc. 2012;75(1):25-8. https://doi.org/10.1016/j. jcma.2011.10.011.

27. Verani JR, McGee L, Schrag SJ. Division of bacterial diseases, National Center for Immunization and Respiratory Diseases, Centers for Disease Control and
Prevention (CDC). Prevention of perinatal group B streptococcal diseaserevised guidelines from CDC, 2010. MMWR Recomm Rep. 2010;59(RR-10):1-36.

28. Mi J, Liu F. Rate of caesarean section is alarming in China. Lancet. 2014; 383(9927):1463-4.

29. Stoll BJ, Hansen NI, Sánchez PJ, Faix RG, et al. Eunice Kennedy Shriver National Institute of Child Health and Human Development neonatal research network. Early onset neonatal sepsis: the burden of group B streptococcal and E. Coli disease continues. Pediatrics. 2011;127(5):817-26. https://doi.org/10.1542/peds.2010-2217.

30. Eberly MD, Rajnik M. The effect of universal maternal screening on the incidence of neonatal early-onset group B streptococcal disease. Clin Pediatr (Phila). 2009 May;48(4):369-75. https://doi.org/10.1177/ 0009922808325455

31. Le Doare K, Jarju S, Darboe S, Warburton F, et al. Risk factors for group B Streptococcus colonisation and disease in Gambian women and their infants. $J$ Inf Secur. 2016;72(3):283-94. https:/doi.org/10.1016/j.jinf.2015.12.014.

32. Puopolo KM, Madoff LC, Eichenwald EC. Early-onset group B streptococcal disease in the era of maternal screening. Pediatrics. 2005;115(5):1240-6.

33. Honest H, Sharma S, Khan KS. Rapid tests for group B Streptococcus colonization in laboring women: a systematic review. Pediatrics. 2006;117(4): 1055-66.

34. El Helali N, Giovangrandi Y, Guyot K, Chevet K, et al. Cost and effectiveness of intrapartum group B streptococcus polymerase chain reaction screening for term deliveries. Obstet Gynecol. 2012;119(4):822-9.

35. Edwards RK, Novak-Weekley SM, Koty PP, Davis T, et al. Rapid group B streptococci screening using a real-time polymerase chain reaction assay. Obstet Gynecol. 2008;111(6):1335-41.

36. Brigtsen AK, Jacobsen AF, Dedi L, Melby KK, et al. Maternal colonization with group B Streptococcus is associated with an increased rate of infants transferred to the neonatal intensive care unit. Neonatology. 2015;108(3): 157-63. https://doi.org/10.1159/000434716.

37. Mikamo H, Johri AK, Paoletti LC, Madoff LC, et al. Adherence to, invasion by, and cytokine production in response to serotype VIII group B streptococci. Infect Immun. 2004;72(8):4716-22.

38. Borghesi A, Stronati M, Fellay J. Neonatal group B streptococcal disease in otherwise healthy infants: failure of specific neonatal immune responses. Front Immunol. 2017;8:215. https://doi.org/10.3389/fimmu.2017.00215.

Ready to submit your research? Choose BMC and benefit from:

- fast, convenient online submission

- thorough peer review by experienced researchers in your field

- rapid publication on acceptance

- support for research data, including large and complex data types

- gold Open Access which fosters wider collaboration and increased citations

- maximum visibility for your research: over $100 \mathrm{M}$ website views per year

At BMC, research is always in progress.

Learn more biomedcentral.com/submissions 